\title{
Antitumor effects of saikosaponin b2 on breast cancer cell proliferation and migration
}

\author{
QING MA $^{1 *}$, FANG-FANG GAO $^{1,2^{*}}$, XIN HE $^{1}, \mathrm{KAI} \mathrm{LI}^{2}$, YANG GAO $^{1}$, XIAO-LONG XU ${ }^{2}$, NAN-HUI JIANG ${ }^{1}$, \\ LIANG DING ${ }^{1}$, WEN-JING SONG ${ }^{1}$, YAN-QI HE ${ }^{2}$, WEN-TING PAN ${ }^{2}$, LEI WEI $^{2}$ and JING-WEI ZHANG ${ }^{1}$ \\ ${ }^{1}$ Department of Breast and Thyroid Surgery, Zhongnan Hospital, Hubei Key Laboratory of Tumour Biological Behaviours, \\ Hubei Cancer Clinical Study Centre; ${ }^{2}$ Department of Pathology and Pathophysiology, Hubei Provincial Key Laboratory of \\ Developmentally Originated Disease, School of Basic Medical Sciences, Wuhan University, Wuhan, Hubei 430071, P.R. China
}

Received August 16, 2018; Accepted April 5, 2019

DOI: $10.3892 / \mathrm{mmr} .2019 .10385$

\begin{abstract}
Saikosaponin b2 (SSb2) can be extracted from Bupleurum spp. roots (Radix Bupleuri), which belongs to the Umbelliferae family. The current study aimed to explore the effects of SSb2 on proliferation of breast cancer cells and to identify the mechanism by which $\mathrm{SSb} 2$ affects breast cancer cell migration. mRNA expression levels of STAT3 and vasodilator-stimulated phosphoprotein (VASP) were determined and increased expression was observed in 16 breast cancer tissues compared with the paracancerous tissues. MTT, wound healing, colony formation assays and western blot suggested that SSb2 inhibited MCF-7 proliferation and migration. It was further identified by western blot analysis that SSb2 treatment reduced levels of phosphorylated STAT3, VASP, matrix metallopeptidase (MMP) 2 and MMP9 in MCF-7 compared with the untreated cells. In addition, it was demonstrated that inhibition of STAT3 phosphorylation decreased VASP expression levels and induction of STAT3 phosphorylation increased VASP levels. Furthermore, it was observed that the treatment of Kunming mice with SSb2 at $30 \mathrm{mg} / \mathrm{kg} /$ day for 30 days induced no obvious changes in the liver or kidney tissues, as determined by haematoxylin and eosin staining. In conclusion, these results indicated that $\mathrm{SSb} 2$ may be a potential antitumor drug for the treatment of breast cancer, which acts by suppressing proliferation and migration by downregulating the STAT3 signalling pathway and inhibiting the expression of VASP, MMP2 and MMP9 expression.
\end{abstract}

Correspondence to: Professor Jing-Wei Zhang, Department of Breast and Thyroid Surgery, Zhongnan Hospital, Hubei Key Laboratory of Tumour Biological Behaviours, Hubei Cancer Clinical Study Centre, Wuhan University, 169 Donghu Road, Wuhan, Hubei 430071, P.R. China

E-mail: zjwzhang68@hotmail.com

*Contributed equally

Key words: saikosaponin b2, proliferation, migration, breast cancer

\section{Introduction}

Breast cancer is the most common diagnosed malignancy in women and the leading cause of malignancy-associated mortality in women worldwide, with an estimated 270,000 new cases and 70,000 mortalities recorded in China in 2015 (1). The majority of mortalities of patients with breast cancer are due to cancer metastasis, and studies have reported that breast cancer invasion and metastasis are closely associated with multiple signalling pathways. A study has suggested that STAT3, a mediator in the Janus kinase (JAK)/STAT signalling pathway, has an important role in promoting metastasis in breast cancer (2). Cell proliferation and tumour metastasis are associated with disorders of cell signal transduction pathways, which makes it important to focus on identifying novel antitumor drugs targeting the abnormal signalling systems in tumour cells.

The current study explored the effects of saikosaponin b2 (SSb2) on the metastasis of breast cancer by studying the JAK/STAT signalling pathway. STAT3 is a member of the STAT family and its abnormal activation has an important role in invasion and metastasis of various types of tumour $(3,4)$. Studies have demonstrated that activated STAT3 increases the transcriptional activity of the matrix metallopeptidase 2 (MMP2) promoter region and upregulates MMP2 protein expression (5).

Bupleurum is used as a herbal therapy that is considered to relieve liver qi stagnation in traditional Chinese herbal medicine (6). Bupleurum has various properties, including immunoregulation, protection of the liver and gall bladder, and antifever, anti-inflammatory, sedative, analgesic, antiviral and antitumor effects (7-9). Pharmacological analysis suggests that the pharmacological effects of Bupleurum are mediated by saikosaponins, which are the major active compounds in Bupleurum. Saikosaponins are triterpenoids, which are subdivided into saikosaponin a, b1, b2, c and d (10). Saikosaponin a (SSa), Saikosaponin c (SSc) and Saikosaponin d (SSd) exert anti-inflammatory effects (11-13), and SSa and SSd inhibit cancer cell proliferation and invasion (14-16). SSa induces apoptosis in MCF-7 cells and the process may be regulated by the Bcl-2 family and dependent on p53/p21 signalling pathway (14). SSd inhibits NF- $\mathrm{B}$ and STAT3 phosphorylation 
in acetaminophen-induced hepatotoxicity in mice (17). SSa is an epimer of SSd that further inhibits NF- $\kappa \mathrm{B}$ activation in lipopolysaccharide-induced RAW264.7 cells (12). SSb2 can be extracted from Bupleurum spp. roots (Radix Bupleuri). $\mathrm{SSb} 2$ is another active compound present in saponin; however, there is limited research on the effects of SSb2. The aim of the current study was to elucidate the pharmacological effects and molecular mechanisms of SSb2 in inhibiting breast cancer cell proliferation and migration.

\section{Materials and methods}

Cell culture and plasmid transfection. MCF-7 human breast cancer cells were obtained from the Department of Pathophysiology, Basic Medical College of Wuhan University (Wuhan, China). Cells were maintained in DMEM (HyClone; GE Healthcare Life Sciences) supplemented with $10 \%$ FBS (Gibco; Thermo Fisher Scientific, Inc.) and antibiotics (100 U/ml penicillin and $100 \mathrm{U} / \mathrm{ml}$ streptomycin) at $37^{\circ} \mathrm{C}$ in a humidified incubator supplemented with $5 \% \mathrm{CO}_{2}$. To inhibit expression of pSTAT3 and VASP, MCF-7 cells were treated with $15 \mu \mathrm{M}$ NSC74859 for $24 \mathrm{~h}$ before western blot analysis. A total of $1.5 \times 10^{5}$ cells were plated in $2 \mathrm{ml}$ growth medium without antibiotics in 6-well plates. A total of $10 \mu \mathrm{l}$ Lipofectamine $^{\mathrm{TM}}$ 2000 and $4 \mu \mathrm{g}$ pCGN-HAM-STAT3 or pCGN-HAM-vector diluted in $50 \mu \mathrm{l}$ Opti-MEMI Reduced Serum medium were mixed gently and incubated for $20 \mathrm{~min}$ at room temperature. pCGN-HAM-STAT3 was previously constructed in our laboratory with primer, STAT3, forward, 5'-AATCTCGAGGGA TGGCCCAATGGAATCAGCTA-3', and reverse, 5'-AAT GTCGACTCACATGGGGGAGGTAGCGC-3'. The resultant mixture was added to $1.5 \times 10^{5}$ cells and $100 \mu \mathrm{l}$ Opti-MEMI medium was added to a blank control groups. Cells were incubated for $48 \mathrm{~h}$ prior to analysis of transgene expression. MCF-7 cells were also treated with IL-6 $\left(10 \mathrm{ng} / \mathrm{ml}, 37^{\circ} \mathrm{C}\right)$ for $30 \mathrm{~min}$ before western blot analysis to explore the effect of IL-6-induced STAT3 phosphorylation on VASP protein expression.

Human breast cancer samples. A total of 16 human breast cancer and matched adjacent tissues were collected between July 2016 to May 2017 at Zhongnan Hospital of Wuhan University (Wuhan, China). Prior to the surgery, patients signed informed consent forms for the present study, which included consent for the use of their tissue for research. The inclusion criteria were: i) Adults aged 18-60; ii) primary invasive tumors; iii) no metastasis; iv) no previous therapy prior to surgical resection. The exclusion criteria were: i) 18> age $>60$; ii) male breast cancer; iii) with metastasis; iv) recurrent lesions. The study was endorsed by the Ethics Committee of the Zhongnan Hospital of Wuhan University and was conducted in accordance with the principles of the Declaration of Helsinki.

Reverse transcription-quantitative PCR (RT-qPCR) assays. Total RNA was extracted from breast cancer and matched normal tissues using TRIzol reagent (Invitrogen; Thermo Fisher Scientific, Inc.) and was used for first-strand cDNA synthesis using the RevertAid ${ }^{\mathrm{TM}}$ kit (Fermentas; Thermo Fisher Scientific, Inc.). For reverse transcription, RNA strand was incubated with $1 \mu \mathrm{l}$ RNAase inhibition $2 \mu 110 \mathrm{mM}$ dNTP mix at $37^{\circ} \mathrm{C}$ for 5 mins. cDNA was synthetized with reverse transcriptase at $42^{\circ} \mathrm{C}$ for $60 \mathrm{mins}$ and $72^{\circ} \mathrm{C}$ for $10 \mathrm{mins}$. PCR amplification of cDNA was conducted with $10 \mu \mathrm{l}$ of $2 \mathrm{X}$ SYBR Master mix (Toyobo Life Science) using the following primers: STAT3, forward 5'-GCACTTGTAATGGCGTCT TCA-3' and reverse 5'-TCTAGCTGTTCTGCCTCACCT-3'; vasodilator-stimulated phosphoprotein (VASP), forward 5'-AAAGTCAGCAAGCAGGAGGA-3' and reverse 5'-ATT CATCCTTGGGGGTTTTC-3'; and internal control GAPDH, forward 5'-TGATGACATCAAGAAGGTGGTGAAG-3' and reverse 5'-TCCTTGGAGGCCATGTGGGCCAT-3'. Cycling conditions were $95^{\circ} \mathrm{C}$ for $10 \mathrm{sec}, 65^{\circ} \mathrm{C}$ for $20 \mathrm{sec}$ and $72^{\circ} \mathrm{C}$ for $15 \mathrm{sec}$ (40 cycles).

Cell proliferation assays. MTT assays (Amresco, LLC) were performed to determine proliferation. Cells were seeded in 96-well plates at $2 \times 10^{3}$ cells/well and incubated. Cells were treated with various $\mathrm{SSb} 2$ concentrations $(0,0.1,0.2,0.5,1$, $2,5,10,20$ and $50 \mu \mathrm{M}$ ) for $48 \mathrm{~h}$. Following treatment with $100 \mu \mathrm{l}$ MTT $(5 \mathrm{mg} / \mathrm{ml})$, cells were incubated for further $4 \mathrm{~h}$ at $37^{\circ} \mathrm{C}$. Medium was discarded and $150 \mu \mathrm{l}$ DMSO was added (Sigma-Aldrich; Merck KGaA). Absorbance at $490 \mathrm{~nm}$ was determined using an ELISA plate reader (Infinite ${ }^{\circledR} 200$ PRO; Tecan Group, Ltd.). The viability of SSb2-treated cells was calculated by comparing the absorbance of each group with DMSO-treated cells, which were arbitrarily assigned $100 \%$.

Cell migration assay. The effect of SSb2 on breast cancer cell migration was measured using wound-healing assays. Cells were plated at $1 \times 10^{5}$ cells/well in 6-well plates and allowed to grow to $60-70 \%$ confluence. Cells were serum-starved for $12 \mathrm{~h}$, washed twice with PBS and supplied with DMEM supplemented with $10 \%$ FBS and various concentrations of SSb2 $(0.2,1$ and $5 \mu \mathrm{M})$. Wounds were created by scratching across the cell monolayer and cells within the same fields of view were captured at 0,24 and $48 \mathrm{~h}$ under a light microscope (Olympus, Japan). The cell migration area was measured between cut regions using Image J software (V1.8.0; National Institutes of Health) and normalized to control cells.

Colony formation assay. Cells treated with varying concentrations of $\operatorname{SSb} 2(0.2,2,10,20$ and $50 \mu \mathrm{M})$ for $48 \mathrm{~h}$ were plated at 200 cells/dish and incubated at $37^{\circ} \mathrm{C}$ in a $5 \% \mathrm{CO}_{2}$ incubator. Following treatment with different concentrations of SSb2, the cells were incubated for two additional weeks and the clones stained with crystal violet $(0.5 \%, \mathrm{~m} / \mathrm{v})$ for $30 \mathrm{mins}$ at room temperature. Cells were washed with PBS ( $4 \times 5 \mathrm{~min})$, clones were counted and images were captured. Clone formation rate $(\%)=($ number of clones/number of inoculated cells $) \times 100$.

Western blot analysis. Following washes with PBS, cells were incubated in ice-cold RIPA assay buffer $(20 \mathrm{mM}$ Tris- $\mathrm{HCl}$ $\mathrm{pH} 7.5,1 \mathrm{mM}$ phenyl-methylsulfonylfluoride, $150 \mathrm{mM} \mathrm{NaCl}$, $10 \mu \mathrm{g} / \mathrm{ml}$ leupeptin, $10 \mu \mathrm{g} / \mathrm{ml}$ aprotinin, $0.25 \%$ deoxycholate, $1.5 \mathrm{mM} \mathrm{MgCl}{ }_{2}, 1 \mathrm{mM}$ egtazic acid, $10 \mathrm{mM} \mathrm{NaF}, 1 \%$ Triton $\mathrm{X}-100$ and $10 \mathrm{mM}$ pervanadate). After $15 \mathrm{~min}$ on the ice, mixtures were centrifuged $(15,000 \times \mathrm{g}, 15 \mathrm{~min})$ to extract proteins. A Coomassie Brilliant Blue assay was used to determine the protein concentration in the supernatant. Lysates 

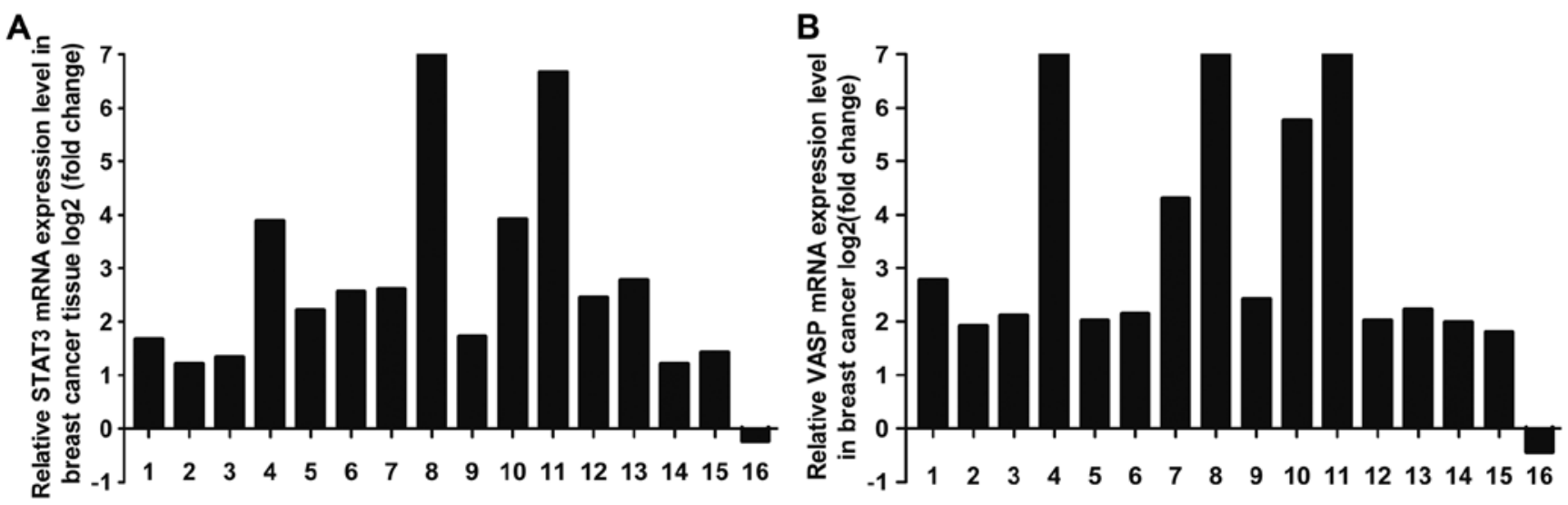

Figure 1. STAT3 and VASP mRNA expression are elevated in breast cancer tissues compared with adjacent normal tissue. Reverse transcription-quantitative PCR analysis was used to determine (A) STAT3 and (B) VASP mRNA levels in 16 pairs of breast cancer and adjacent tissues. P<0.05 (tumour vs. adjacent tissue). Each experiment was repeated three times. VASP, vasodilator-stimulated phosphoprotein.

were mixed with $5 \mathrm{X}$ sample buffer containing 2-mercaptoethanol and boiled for 5 min prior to loading onto $12 \%$ gels and separation by SDS-PAGE. Proteins were then transferred to nitrocellulose membranes over $2 \mathrm{~h}$. Membranes were incubated at $4^{\circ} \mathrm{C}$ overnight with antibodies, following a blocking with $5 \%(\mathrm{w} / \mathrm{v}) \mathrm{BSA}$ in Tris-buffer for $1.5 \mathrm{~h}$ at room temperature. Anti-VASP (1:1,000; cat. no. sc-376226), anti-STAT3 (1:2,000; cat. no. sc-293151), anti-phospho (p)STAT3 (1:2,000; cat. no. sc-56747), anti-c-myc (1:1,000; cat. no. sc-53854), anti-cyclin D1 (1:1,000; cat. no. sc-450), anti-MMP2 (1:1,000; cat. no. sc-13594), anti-MMP9 (1:1,000; cat. no. sc-21733) and anti-GAPDH (1:2,000; cat. no. sc-66163) primary antibodies (Santa Cruz Biotechnology, Inc.) were diluted in 1X TBS containing $0.1 \%$ Tween 20 with 5\% BSA. Following three washes with TBS containing $0.1 \%$ Tween 20 , blots were incubated with horseradish peroxidase-conjugated secondary antibody (1:2,000; cat: 516102; Santa Cruz Biotechnology, Inc.) at room temperature for $1 \mathrm{~h}$. An ECL reagent kit (Axygen; Corning Inc., Corning, NY, USA) was used to detect protein bands. Band Scan (version 5.0, Glyko lnc.) was used to quantitatively analyze each band for statistical comparison.

Haematoxylin and eosin $(H \& E)$ staining. H\&E staining was used to assess the hepatotoxicity and nephrotoxicity in Kunming mice treated with SSb2. Kunming mice $(n=12$, 8-weeks old, 18-24 g) were maintained under sterile conditions and fed with sterile feed and water at $18^{\circ} \mathrm{C}$ and a $12-\mathrm{h}$ light/dark cycle. The mice were obtained from Animal Biosafety Level 3 Laboratory of Wuhan University and randomly divided into 2 groups with 6 females in each. Mice in the experimental group were administered SSb2 $(30 \mathrm{mg} / \mathrm{kg})$ daily by intraperitoneal injection for 1 month and the control group was administered same volume of saline. The experimental mice were kept at a constant $20^{\circ} \mathrm{C}$ with $50 \%$ humidity and with regular clean food and water. Fresh liver and kidney tissues were obtained from the mice and tissues were cut into small pieces, fixed with $4 \%$ paraformaldehyde for $24 \mathrm{~h}$ at room temperature, embedded in paraffin and stained with H\&E. The slices were stained with hematoxylin for $10 \mathrm{~min}$ and eosin for $30 \mathrm{sec}$ at $60^{\circ} \mathrm{C}$. Paraffin sections were observed under a light microscope (magnification, $\mathrm{x} 400$ ). All experiments followed the Guidelines for Animal Experimentation of the Wuhan University (Wuhan, China) and protocols were approved by the Ethics Committee for Animal Experimentation.

Statistical analysis. Data are presented as the mean \pm SEM representing multiple experiments. Student's t-tests were performed to compare data from two groups, and differences between three or more groups were analysed using one-way ANOVA analysis. Tukey's honestly significant difference procedure was used for post hoc analysis. $\mathrm{P}<0.05$ was considered to indicate a statistically significant difference.

\section{Results}

STAT3 and VASP $m R N A$ is increased in human breast cancer tissues. To detect STAT3 and VASP mRNA expression in breast cancer tissues, RT-qPCR analysis was performed. As presented in Fig. 1, STAT3 and VASP mRNA expression in cancer tissues were significantly increased compared with the adjacent normal tissues $(\mathrm{P}<0.05)$.

SSb2 inhibits proliferation, migration and colony numbers of MCF-7 breast cancer cells. To study the effect of SSb2 on MCF-7 proliferation, cells were treated with $\operatorname{SSb} 2(0.1,0.2$, $0.5,1,2,5,10,20$ and $50 \mu \mathrm{M})$ for $48 \mathrm{~h}$. Following treatment, MTT assays were performed to measure cell proliferation. As presented in Fig. 2A, the cell proliferation rate was significant inhibited compared with the control group in a dose-dependent manner $(\mathrm{P}<0.05)$. Western blot analysis also was performed following cell treatment with $5 \mu \mathrm{M} \mathrm{SSb} 2$ for $48 \mathrm{~h}$. As presented in Fig. $2 \mathrm{~B}$, treatment with $5 \mu \mathrm{M} \mathrm{SSb} 2$ significantly reduced the expression of c-myc and cyclin D1, which are related to cell proliferation in the STAT3 signalling pathway, compared with the control $(\mathrm{P}<0.05)$.

To observe the effect of SSb2 on the migration of breast cancer cells, cells were treated with $\operatorname{SSb} 2(0.2,1$ and $5 \mu \mathrm{M})$ for 24 and $48 \mathrm{~h}$. Following treatment, wound-healing assays were performed to evaluate MCF-7 migration. As presented in Fig. 2C, following treatment with $\mathrm{SSb} 2$, cell migration rates decreased along with the increased concentration of SSb2 at 24 or $48 \mathrm{~h}$ in a dose-dependent manner. 
A

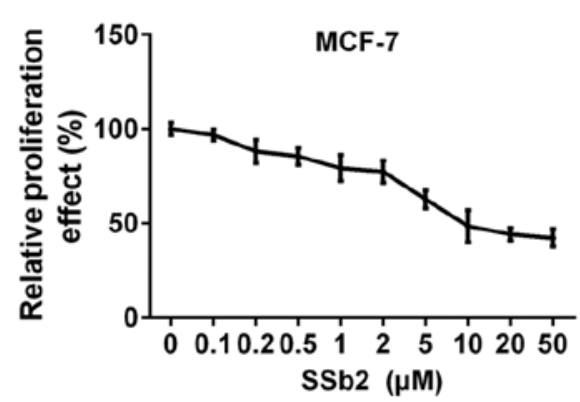

B

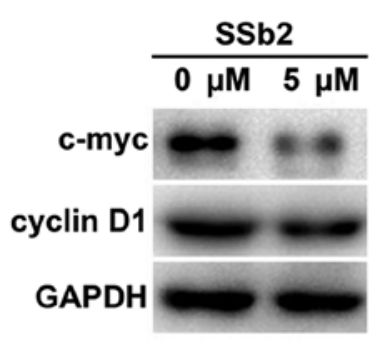

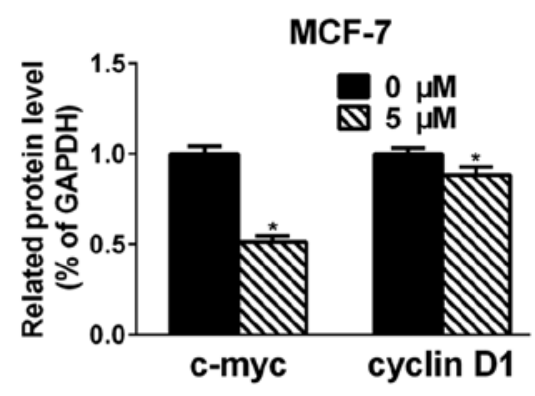

C
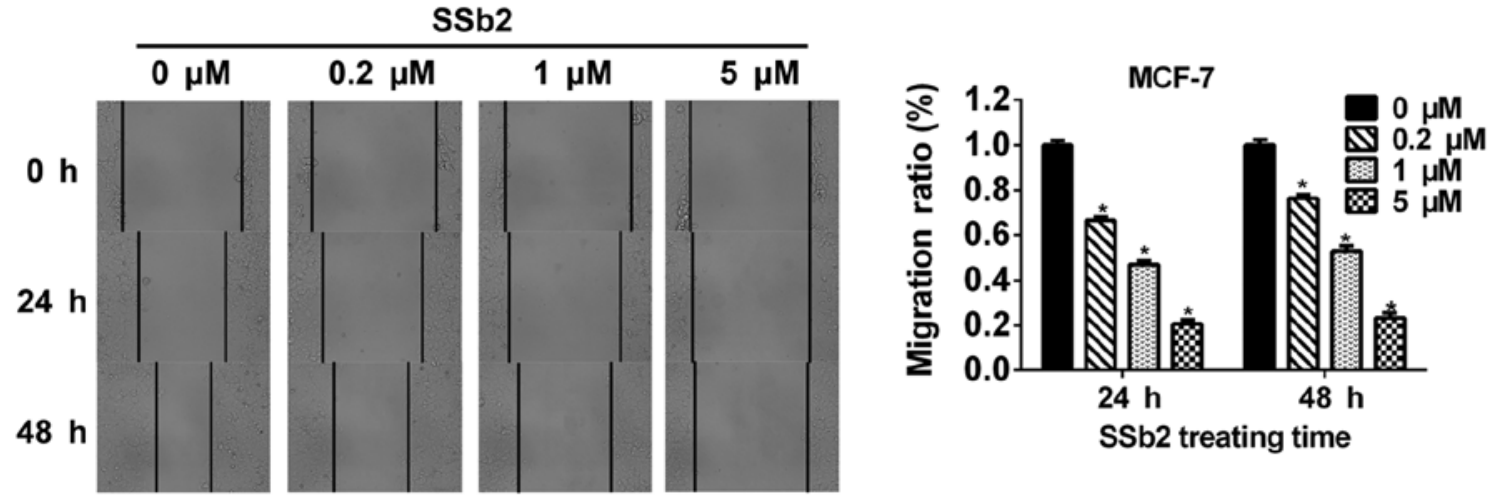

D
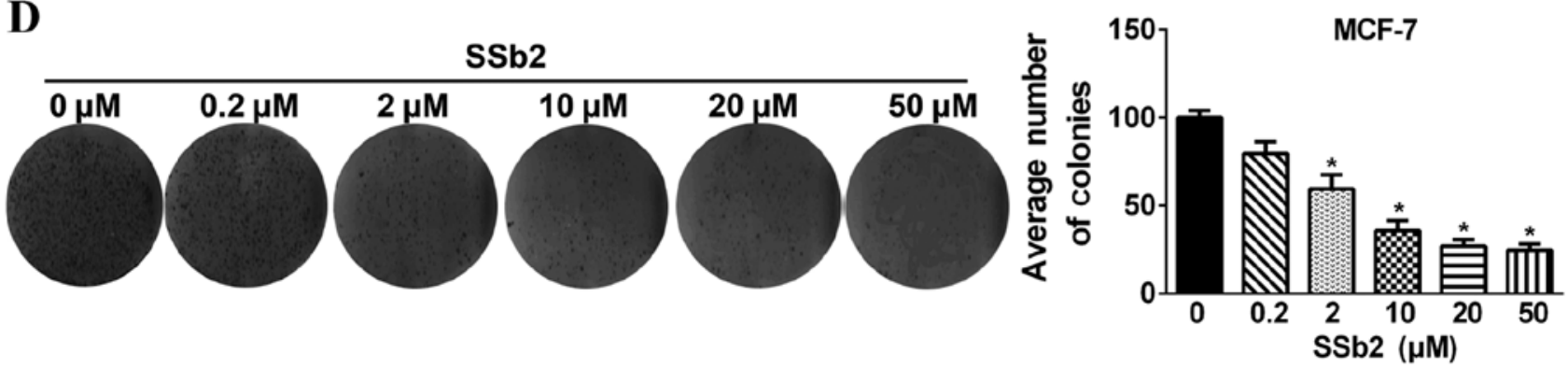

Figure 2. SSb2 inhibits proliferation, migration and clone number of MCF-7 cells. (A) MTT assay performed with MCF-7 cells treated with various SSb2 $(0.1-50 \mu \mathrm{M})$ for $48 \mathrm{~h}$. (B) Western blot analysis performed with MCF-7 cells treated with SSb2 $(5 \mu \mathrm{M})$ for $48 \mathrm{~h}$. GAPDH was used as a loading control and experiments were performed in triplicate. (C) Wound-healing assays performed with MCF-7 cells treated with varying concentrations of SSb2 (0.2, 1 and $5 \mu \mathrm{M})$ for 24 and $48 \mathrm{~h}$. (D) Clone formation ability of MCF-7 cells treated with SSb2 (0.2, 2, 10, 20 and $50 \mu \mathrm{M})$ for 48 h. Each experiment was repeated three times and data was shown as mean \pm standard deviation. ${ }^{*} \mathrm{P}<0.05$ vs. control. SSb2, saikosaponin b2.

To determine whether SSb2 affects the clonal formation ability of MCF-7 breast cancer cells, colony formation assays were performed. Varying concentrations of $\operatorname{SSb} 2(0.2,2,10$, 20 and $50 \mu \mathrm{M}$ ) were used to treat MCF-7 cells for $48 \mathrm{~h}$. As presented in Fig. 2D, the colony formation ability was significantly suppressed using $2,10,20$ or $50 \mu \mathrm{M} \mathrm{SSb} 2$ compared with the control $(\mathrm{P}<0.05)$ in a dose-dependent manner.

SSb2 affects pSTAT3, STAT3 and VASP protein levels. To study effects of SSb2 on pSTAT3, STAT3 and VASP protein levels in MCF-7 cells, western blot analysis was performed following cell treatment with $\mathrm{SSb} 2(0.2,0.5$ and $1 \mu \mathrm{M})$ for $48 \mathrm{~h}$. As presented in Fig. 3, treatment with 0.2, 0.5 and $1 \mu \mathrm{M}$ $\mathrm{SSb} 2$ significantly reduced pSTAT3 in MCF-7 cells compared with the control $(\mathrm{P}<0.05)$. SSb2 at $1 \mu \mathrm{M}$ significantly reduced STAT3 expression compared with the control $(\mathrm{P}<0.05)$, while 0.2 and $0.5 \mu \mathrm{M} \mathrm{SSb} 2$ had no significant effect on STAT3 expression. Analysis of the pSTAT3/STAT3 ratio demonstrated that STAT3 phosphorylation was reduced by 0.5 and
$1 \mu \mathrm{M} \mathrm{SSb} 2$. In addition, 0.5 and $1 \mu \mathrm{M}$ of SSb2 significantly reduced VASP expression in MCF-7 cells compared with the untreated control $(\mathrm{P}<0.05)$.

Inhibition of STAT3 phosphorylation affects VASP expression. To investigate whether SSb2 affected VASP protein expression by inhibiting STAT3 phosphorylation, cells were treated with NSC74859 $(15 \mu \mathrm{M})$ a specific inhibitor of STAT3 phosphorylation and pSTAT3, STAT3 and VASP levels were determined by western blot. As presented in Fig. 4, pSTAT3 and VASP levels in the NSC74859-treated cells were significantly decreased compared with the control $(\mathrm{P}<0.05)$, while STAT3 levels exhibited no significant changes.

STAT3 phosphorylation induced by interleukin-6 (IL-6) affects VASP levels. To observe whether STAT3 phosphorylation affects VASP expression, STAT3, pSTAT3 and VASP levels were determined in STAT3 overexpressing cells or following IL-6 treatment of MCF-7 cells. As presented 
A

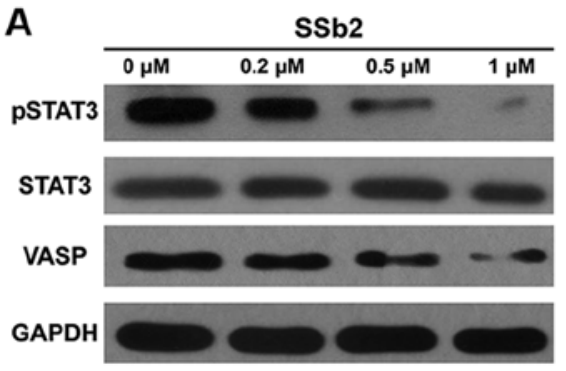

B

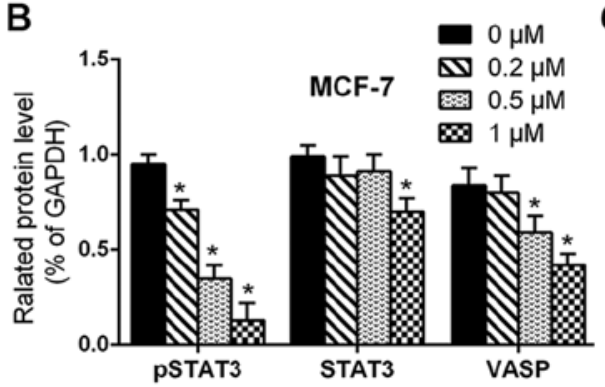

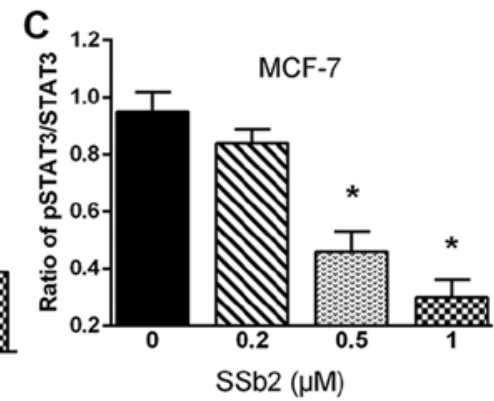

Figure 3. SSb2 affects pSTAT3, STAT3 and VASP level. (A) Western blot images, and (B) semi-quantitative analysis of pSTAT3, STAT3 and VASP levels and $(\mathrm{C})$ the ratio of pSTAT3/STAT3 in MCF-7 cells treated with varying concentrations of SSb2 $(0.2,0.5 \mathrm{and} 1 \mu \mathrm{M})$ for $48 \mathrm{~h}$. GAPDH was used as a loading control and experiments were performed in triplicate. Each experiment was repeated three times and data was shown as mean \pm standard deviation. ${ }^{*} \mathrm{P}<0.05$ vs. control. SSb2, saikosaponin b2; pSTAT, phospho-STAT; VASP, vasodilator-stimulated phosphoprotein.
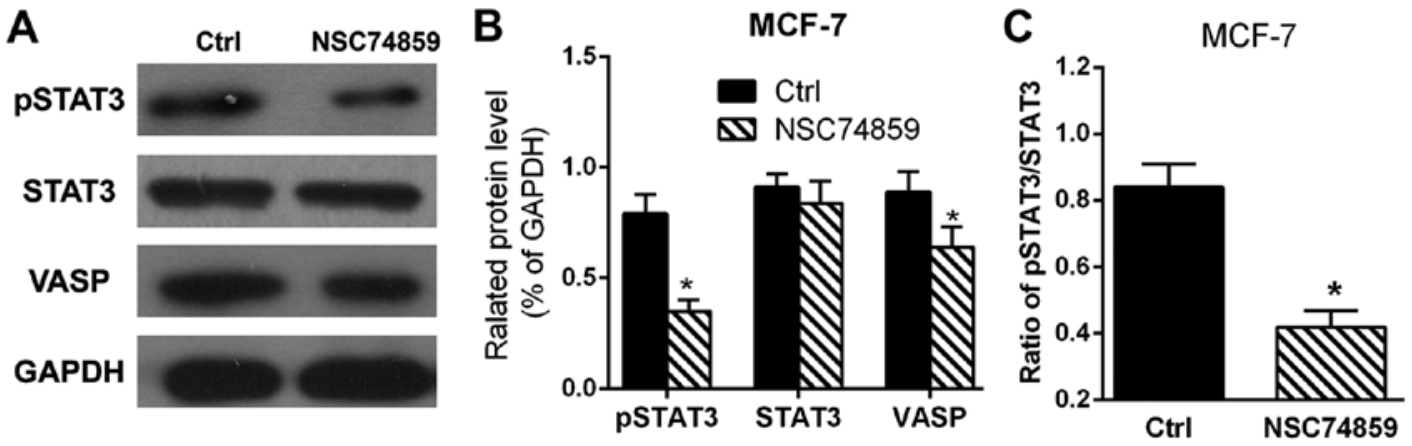

Figure 4. NSC74859 treatment affects pSTAT3 and VASP level. (A) Western blot images, and (B) semi-quantitative analysis of pSTAT3, STAT3 and VASP levels and (C) the ratio of pSTAT3/STAT3 in MCF-7 cells treated with NSC74859 (15 $\mu \mathrm{M})$ for $24 \mathrm{~h}$. GAPDH was used as a loading control and experiments were performed in triplicate. Each experiment was repeated three times and data was shown as mean \pm standard deviation. ${ }^{*} \mathrm{P}<0.05$ vs. control. pSTAT, phospho-STAT; VASP, vasodilator-stimulated phosphoprotein.

in Fig. 5, STAT3 and pSTAT3 levels in STAT3 overexpressing MCF-7 cells were significantly increased compared to the control $(\mathrm{P}<0.05)$. Stimulation with IL-6 significantly increased STAT3, pSTAT3 and VASP levels compared with the control $(\mathrm{P}<0.05)$. Treatment of STAT3 overexpressing cells with IL-6 significantly increased STAT3, pSTAT3 and VASP levels compared with the control $(\mathrm{P}<0.05)$. In conclusion, VASP level could be only elevated when STAT3 was phosphorylated by IL-6. Thereby, STAT3 phosphorylation induced by IL-6 could affect VASP levels.

SSb2 affects MMP2 and MMP9 expression. To detect the effect of SSb2 on MMP2 and MMP9 expression, MCF-7 cells were treated with $5 \mu \mathrm{M} \mathrm{SSb} 2$ for $48 \mathrm{~h}$ and expression was detected by western blot analysis. As presented in Fig. 6, MMP2 and MMP9 expression was significantly decreased in SSb2-treated cells compared with the control group.

SSb2 exerts no liver or kidney toxicity in Kunming mice. To observe whether SSb2 treatment induces liver or kidney damage, an experimental group of Kunming mice was injected intraperitoneally with $30 \mathrm{mg} / \mathrm{kg} / \mathrm{day} \mathrm{SSb} 2$ for 30 days. Liver and kidney tissues from mice of the experimental and the untreated control groups were H\&E stained. As presented in Fig. 7, no hepatocellular degeneration or necrosis was observed in the experimental group compared with the control group and no inflammatory cells were detected to have infiltrated the hepatic lobules or the portal area (Fig. 7A and B). There was no significant increase in the number of cells in the glomerular capillary loop and no neutrophils and lymphocyte invasion in the experimental compared with the control mice (Fig. 7C and D).

\section{Discussion}

Incidence and mortality rates of patients with breast cancer remain high, ranking second to cervical cancer in developing countries (18). Cancer cell metastasis became the leading cause of death in patients with breast cancer. Saikosaponins are small molecule compounds extracted from the medicinal Bupleurum plants. Studies have revealed that SSd effectively downregulates tumour necrosis factor- $\alpha$-mediated NF- $\kappa B$ signalling pathway to inhibit proliferation and invasion of cancer cells (16). SSd inhibits the NF-кB/STAT3 signalling pathway, protecting against acetaminophen-induced liver injury (17). Another study demonstrated that $\mathrm{SSb} 2$ hinders hepatitis $\mathrm{C}$ virus entry into cells through affecting the E2 protein in the virus, which may useful for anti-hepatitis $C$ virus treatment (19). The current study examined the mechanisms of action of SSb2 on breast cancer cells and explored whether the antitumor effect of SSb2 in breast cancer was associated with the JAK/STAT signalling pathway.

The JAK/STAT signalling pathway is involved in cell proliferation, differentiation, apoptosis, immune regulation 

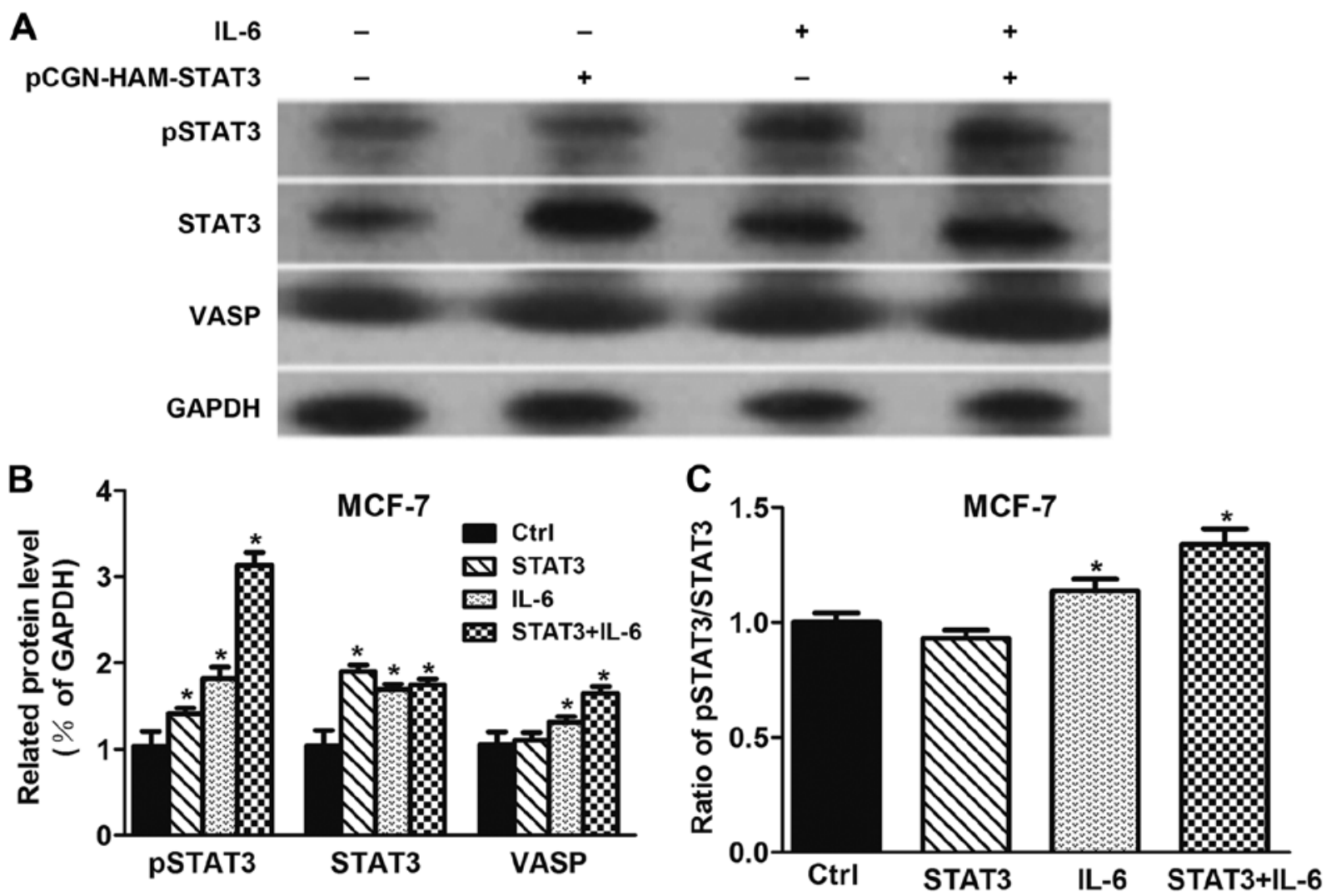

Figure 5. IL-6-induces upregulation of pSTAT3 and VASP levels. (A) Western blot images and (B) semi-quantitative analysis of pSTAT3, STAT3 and VASP levels and (C) the ratio of pSTAT3/STAT3 in STAT3 overexpressing MCF-7 treated with IL-6 for 30 min. GAPDH was used as a loading control and experiments were performed in triplicate. Each experiment was repeated three times and data was shown as mean \pm standard deviation. "P<0.05 vs. control. IL-6, interleukin-6; pSTAT, phospho-STAT; VASP, vasodilator-stimulated phosphoprotein.

A

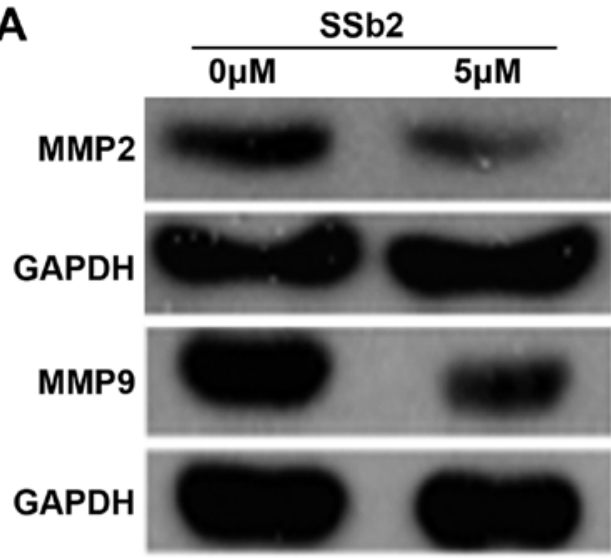

B

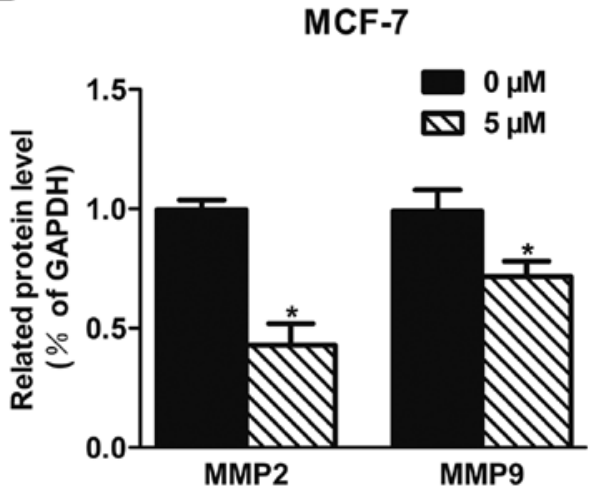

Figure 6. SSb2 treatment reduces MMP2 and MMP9 expression levels in MCF-7 cells. (A) Western blot images and (B) semi-quantitative analysis of MMP2 and MMP9 in MCF-7 cells treated with SSb2 $(5 \mu \mathrm{M})$ for $48 \mathrm{~h}$. GAPDH was used as a loading control and experiments were performed in triplicate. Each experiment was repeated three times and data was shown as mean \pm standard deviation. ${ }^{*} \mathrm{P}<0.05$ vs. control. SSb2, saikosaponin b2; MMP, matrix metallopeptidase.

and other biological processes. The STAT family contains seven protein members, including STAT1, STAT2, STAT3, STAT4, STAT5a, STAT5b and STAT6. Of these, STAT3 is closely associated with tumorigenesis and has received increasing attention. STAT3 has an important role in cellular signal transduction (20). It transmits signals from outside the cell to the nucleus and induces the transcription of target genes. Epidermal growth factor activates the STAT3 signalling pathway in prostate cancer cells and enhances the transcriptional activity of its downstream targets. Small interfering RNA targeting STAT3 reduces the ability of cell migration (21). Another study reported that STAT3 inhibition significantly reduces proliferation of prostate cancer cells $(22,23)$. In breast cancer, compared with paracancerous tissues, STAT3 expression is markedly increased (3), which is consistent with the results obtained in the current study 

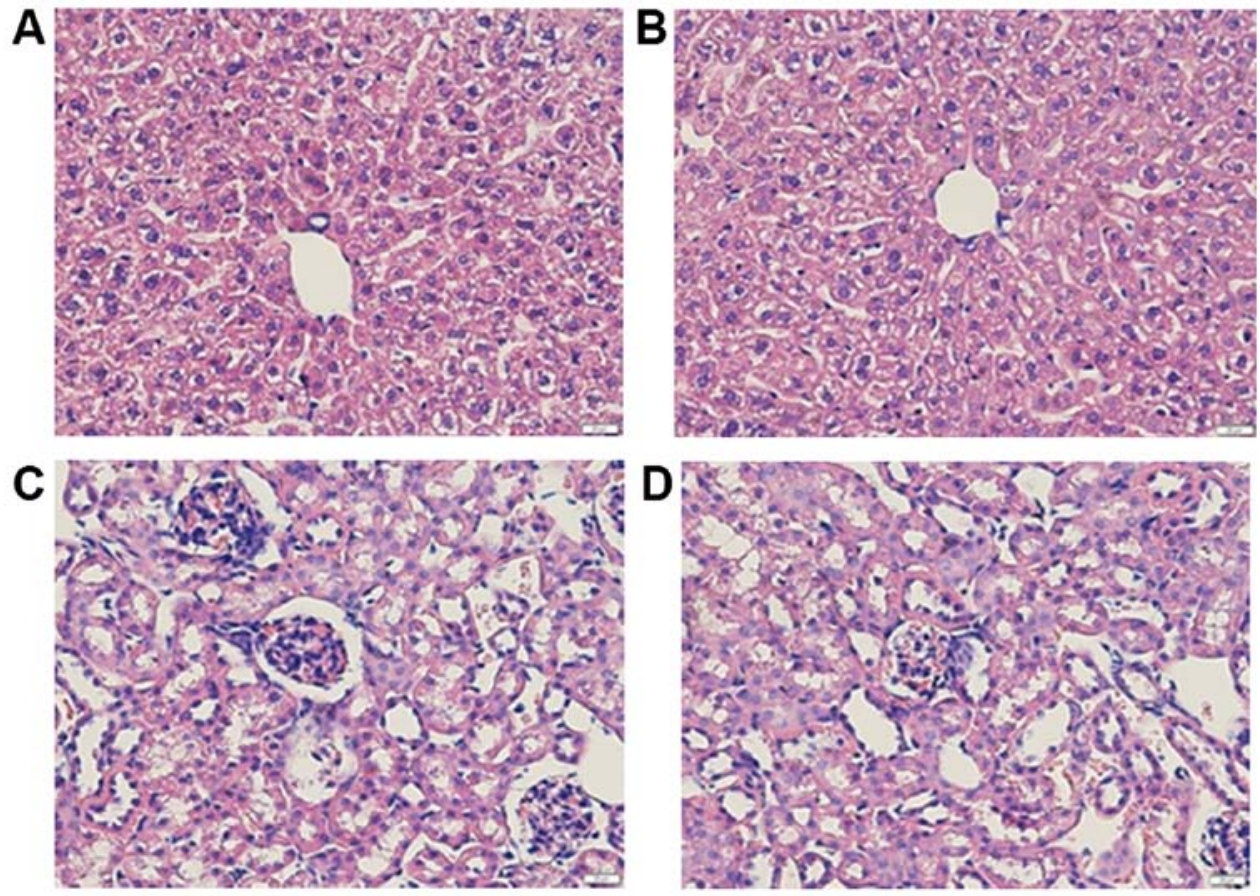

Figure 7. SSb2 does not affect the morphology of the liver or kidney in Kunming mice. In liver samples, compared with (A) the control group, no hepatocellular degeneration or necrosis was detected in (B) the SSb2-treated experimental group and no inflammatory cells infiltrated the hepatic lobules or the portal area. In kidney samples, compared with $(\mathrm{C})$ the control group, the number of cells in the glomerular capillary loop remained constant and no neutrophils and lymphocyte invasion was observed in (D) the SSb2-treated group. (Haematoxylin and eosin staining; magnification, $\mathrm{x} 400$ ). SSb2, saikosaponin b2.

evaluating protein expression in cancer and adjacent tissues of patients with breast cancer.

VASP, an important member of the Ena/VASP family, is an actin-regulating protein in mammalian cells. Within the cells, VASP is mainly located in regions associated with cell adhesion and movement with key roles in the regulation of tumour cell migration and metastasis $(24,25)$. VASP expression is regulated by upstream factors to affect cell metastasis (26). From the perspective of drug intervention, identifying effective VASP-targeting drugs to inhibit cell transfer may provide novel research directions.

MMP 2 and MMP 9 are members of the MMP family that contribute to cancer progression through extracellular matrix degradation, allowing cancer cells to migrate away from primary tumours and metastasise. Particularly, MMP2 is capable of degrading the most abundant type IV collagen in basement membranes. Degradation of the basement membrane is a key step in the progression of most cancer metastases (27). In aggressive breast tumours, MMP2 and MMP9 are highly expressed and associated with poor prognosis (28). In addition, various studies have reported that MMP2 and MMP9 expression is associated with multiple signalling pathways. Formononetin flavonoids inhibit migration and invasion of breast cancer cells by reducing MMP2 and MMP9 expression via the PI3K/AKT signalling pathway (29). Furthermore, studies have revealed that activation of the STAT3 signalling pathway is involved in the upregulation of MMP2 and MMP9 $(30,31)$. Based on these findings, effects of SSb2 on MMP2 and MMP9 expression were evaluated.

To explore the effects of SSb2 on proliferation and migration of breast cancer cells, MTT assays were performed at varying SSb2 concentrations. Treatment of MCF-7 cells with $\mathrm{SSb} 2$ for $48 \mathrm{~h}$ significantly decreased proliferation rates in MCF-7 cells compared with untreated cells. It also demonstrated that $\mathrm{SSb} 2$ significantly reduced protein expression of c-myc and cyclin D1, which are associated with cell proliferation via the STAT3 signalling pathway, compared with the control group. The effects of varying SSb2 concentrations on the migration of MCF-7 cells at different times were investigated using wound-healing experiments. The results suggested that with increasing SSb2 migration rates gradually declined compared with the control group. In a colony formation assay, SSb2 further suppressed colony numbers of MCF-7 cells. The experimental results illustrated that SSb2 suppressed proliferation and migration of breast cancer cells.

To explore the mechanism by which SSb2 inhibited proliferation and migration of breast cancer cells, western blotting was performed to evaluate pSTAT3, STAT3, VASP, MMP2 and MMP9 protein levels. The results demonstrated that SSb2 treatment decreased STAT3 phosphorylation and VASP levels. In subsequent experiments, following the inhibition of STAT3 phosphorylation, pSTAT3 levels decreased significantly and VASP protein expression was reduced compared with the control. The treatment with IL-6, which induces STAT3 activation in MCF-7 cells, led to increased pSTAT3 and VASP protein levels. This suggested that STAT3 phosphorylation in MCF-7 cells may positively regulate VASP expression and that $\mathrm{SSb} 2$ inhibited VASP expression by inhibiting STAT3 phosphorylation. In addition, the current study demonstrated that MMP2 and MMP9 expression was inhibited in MCF-7 cells following treatment with $5 \mu \mathrm{M} \mathrm{SSb} 2$ for $48 \mathrm{~h}$. 
In summary, the current study suggested that SSb2 inhibited proliferation and migration of MCF-7 cells by reducing the activation of STAT3, and inhibiting VASP, MMP2 and MMP9 protein expression. The results further indicated that $\mathrm{SSb} 2$ may reduce the migration of breast cancer cells. A limitation of our study is that only the MCF-7 cell line was investigated, and that the results require validation in other breast cancer cell lines. The current study provided a novel direction for molecular-targeted therapy for patients with breast cancer.

\section{Acknowledgements}

Not applicable.

\section{Funding}

This study received support from the National Natural Science Foundation of China (grant nos. 81472765 and 81572943).

\section{Availability of data and materials}

The datasets used and/or analyzed during the current study are available from the corresponding author on reasonable request.

\section{Authors' contributions}

QM and FG conceived and designed the study, performed the experiments, analysed the data and drafted the manuscript. $\mathrm{XH}, \mathrm{KL}$ and $\mathrm{NJ}$ performed the analysis of data and drafted the manuscript. YG, LD and WS were involved in recruiting patients and collecting patients' samples. XX, YH and WP performed the experiments. JZ and LW supported the funding of study, designed the study and modified the manuscript.

\section{Ethics approval and consent to participate}

Written informed consent was provided by each patient recruited and the present study was approved by the local Human Ethics Committee of Zhongnan Hospital of Wuhan University.

\section{Patient consent for publication}

Not applicable.

\section{Competing interests}

The authors declare that there are no competing interests.

\section{References}

1. Chen W, Zheng R, Baade PD, Zhang S, Zeng H, Bray F, Jemal A, Yu XQ and He J: Cancer statistics in China, 2015. CA Cancer J Clin 66: 115-132, 2016.

2. Lee HT, Xue J, Chou PC, Zhou A, Yang P, Conrad CA, Aldape KD, Priebe W, Patterson C, Sawaya R, et al: Stat3 orchestrates interaction between endothelial and tumor cells and inhibition of Stat 3 suppresses brain metastasis of breast cancer cells. Oncotarget 6: 10016-10029, 2015.

3. Berclaz G, Altermatt HJ, Rohrbach V, Siragusa A, Dreher E and Smith PD: EGFR dependent expression of STAT3 (but not STAT1) in breast cancer. Int J Oncol 19: 1155-1160, 2001.
4. Wang T, Yuan J, Zhang J, Tian R, Ji W, Zhou Y, Yang Y, Song W, Zhang F and Niu R: Anxa2 binds to STAT3 and promotes epithelial to mesenchymal transition in breast cancer cells. Oncotarget 6: 30975-30992, 2015.

5. Xuan X, Li S, Lou X, Zheng X, Li Y, Wang F, Gao Y, Zhang H, $\mathrm{He} \mathrm{H}$ and Zeng Q: Stat3 promotes invasion of esophageal squamous cell carcinoma through up-regulation of MMP2. Mol Biol Rep 42: 907-915, 2015.

6. Law BY, Mo JF and Wong VK: Autophagic effects of Chaihu (dried roots of Bupleurum Chinense DC or Bupleurum scorzoneraefolium WILD). Chin Med 9: 21, 2014.

7. Qi FH, Wang ZX, Cai PP, Zhao L, Gao JJ, Kokudo N, Li AY, Han JQ and Tang W: Traditional Chinese medicine and related active compounds: A review of their role on hepatitis B virus infection. Drug Discov Ther 7: 212-224, 2013.

8. Shah AS and Alagawadi KR: Anti-inflammatory, analgesic and antipyretic properties of Thespesia populnea Soland ex. Correa seed extracts and its fractions in animal models. J Ethnopharmacol 137: 1504-1509, 2011.

9. Wong VK, Li T, Law BY, Ma ED, Yip NC, Michelangeli F, Law CK, Zhang MM, Lam KY, Chan PL and Liu L: Saikosaponin-d, a novel SERCA inhibitor, induces autophagic cell death in apoptosis-defective cells. Cell Death Dis 4: e720, 2013.

10. Yang YY, Tang YZ, Fan CL, Luo HT, Guo PR and Chen JX: Identification and determination of the saikosaponins in Radix bupleuri by accelerated solvent extraction combined with rapid-resolution LC-MS. J Sep Sci 33: 1933-1945, 2010.

11. Sai J, Zhao Y, Shan W, Qu B, Zhang Y, Cheng J, Qu H and Wang Q: Development of an enzyme-linked immunosorbent assay and immunoaffinity column chromatography for saikosaponin d using an anti-saikosaponin d monoclonal antibody. Planta Med 82: 432-439, 2016.

12. Lu CN, Yuan ZG, Zhang XL, Yan R, Zhao YQ, Liao M and Chen JX: Saikosaponin a and its epimer saikosaponin d exhibit anti-inflammatory activity by suppressing activation of NF- $\kappa \mathrm{B}$ signaling pathway. Int Immunopharmacol 14: 121-126, 2012.

13. Ma Y, Bao Y, Wang S, Li T, Chang X, Yang G and Meng X: Anti-inflammation effects and potential mechanism of saikosaponins by regulating nicotinate and nicotinamide metabolism and arachidonic acid metabolism. Inflammation 39: 1453-1461, 2016.

14. Chen JC, Chang NW, Chung JG and Chen KC: Saikosaponin-A induces apoptotic mechanism in human breast MDA-MB-231 and MCF-7 cancer cells. Am J Chin Med 31: 363-377, 2003.

15. Kim BM and Hong SH: Sequential caspase- 2 and caspase- 8 activation is essential for saikosaponin a-induced apoptosis of human colon carcinoma cell lines. Apoptosis 16: 184-197, 2011.

16. Wong VK, Zhang MM, Zhou H, Lam KY, Chan PL, Law CK, Yue PY and Liu L: Saikosaponin-d enhances the anticancer potency of TNF- $\alpha$ via overcoming its undesirable response of activating NF-Kappa B signalling in cancer cells. Evid Based Complement Alternat Med 2013: 745295, 2013.

17. Liu A, Tanaka N, Sun L, Guo B, Kim JH, Krausz KW, Fang Z, Jiang C, Yang J and Gonzalez FJ: Saikosaponin d protects against acetaminophen-induced hepatotoxicity by inhibiting NF- $\mathrm{BB}$ and STAT3 signaling. Chem Biol Interact 223: 80-86, 2014.

18. Fan L, Strasser-Weippl K, Li JJ, St Louis J, Finkelstein DM, Yu KD, Chen WQ, Shao ZM and Goss PE: Breast cancer in China. Lancet Oncol 15: e279-e289, 2014.

19. Lin LT, Chung CY, Hsu WC, Chang SP, Hung TC, Shields J, Russell RS, Lin CC, Li CF, Yen MH, et al: Saikosaponin b2 is a naturally occurring terpenoid that efficiently inhibits hepatitis $\mathrm{C}$ virus entry. J Hepatol 62: 541-548, 2015.

20. Wieczorek M, Ginter T, Brand P, Heinzel T and Krämer $\mathrm{OH}$ : Acetylation modulates the STAT signaling code. Cytokine Growth Factor Rev 23: 293-305, 2012.

21. Rössle C, Carpentier YA, Richelle M, Dahlan W, D'Attellis NP, Fürst $\mathrm{P}$ and Elwyn DH: Medium-chain triglycerides induce alterations in carnitine metabolism. Am J Physiol 258: E944-E947, 1990.

22. Ni Z, Lou W, Leman ES and Gao AC: Inhibition of constitutively activated Stat 3 signaling pathway suppresses growth of prostate cancer cells. Cancer Res 60: 1225-1228, 2000.

23. Gao L, Zhang L, Hu J, Li F, Shao Y, Zhao D, Kalvakolanu DV, Kopecko DJ, Zhao X and Xu DQ: Down-regulation of signal transducer and activator of transcription 3 expression using vector-based small interfering RNAs suppresses growth of human prostate tumor in vivo. Clin Cancer Res 11: 6333-6341, 2005. 
24. Lacayo CI, Pincus Z, VanDuijn MM, Wilson CA, Fletcher DA, Gertler FB, Mogilner A and Theriot JA: Emergence of large-scale cell morphology and movement from local actin filament growth dynamics. PLoS Biol 5: e233, 2007.

25. Chhabra ES and Higgs HN: The many faces of actin: Matching assembly factors with cellular structures. Nat Cell Biol 9: 1110-1121, 2007.

26. Bear JE and Gertler FB: Ena/VASP: Towards resolving a pointed controversy at the barbed end. J Cell Sci 122: 1947-1953, 2009.

27. Mook OR, Frederiks WM and Van Noorden CJ: The role of gelatinases in colorectal cancer progression and metastasis. Biochim Biophys Acta 1705: 69-89, 2004

28. Jezierska A and Motyl T: Matrix metalloproteinase-2 involvement in breast cancer progression: A mini-review. Med Sci Monit 15: RA32-RA40, 2009.
29. Zhou R, Xu L, Ye M, Liao M, Du H and Chen H: Formononetin inhibits migration and invasion of MDA-MB-231 and 4T1 breast cancer cells by suppressing MMP-2 and MMP-9 through PI3K/AKT signaling pathways. Horm Metab Res 46: 753-760, 2014.

30. Xie TX, Wei D, Liu M, Gao AC, Ali-Osman F, Sawaya R and Huang S: Stat 3 activation regulates the expression of matrix metalloproteinase-2 and tumor invasion and metastasis. Oncogene 23: 3550-3560, 2004.

31. Dechow TN, Pedranzini L, Leitch A, Leslie K, Gerald WL, Linkov I and Bromberg JF: Requirement of matrix metalloproteinase-9 for the transformation of human mammary epithelial cells by Stat3-C. Proc Natl Acad Sci USA 101: 10602-10607, 2004. 